\title{
FULL SCALE TEST FOR EXPLOSION WATER BARRIERS IN SMALL CROSS-SECTION GALLERIES
}

\author{
Ljiljana Medic Pejic ${ }^{1}$, Prof. Dr. Enrique Querol Aragón², Prof. Dr. Javier García \\ Torrent $^{1,2}$, Prof. Dr. Carlos Fernández Ramón ${ }^{1,2}$ Prof. Dr. Kazimierz Lebecki ${ }^{3}$ \\ ${ }^{1}$ Official Laboratory of J.M. Madariaga (www.lom.upm.es) - Spain \\ ${ }^{2}$ School of Mines, Technical University of Madrid (www.upm.es) - Spain \\ ${ }^{3}$ School of Occupational Safety, Katowice. Poland
}

\begin{abstract}
Underground coal mines explosions generally arise from the inflammation of a methane/air mixture. This explosion can also generate a subsequent coal dust explosion. Traditionally such explosions have being fought eliminating one or several of the factors needed by the explosion to take place. Although several preventive measures are taken to prevent explosions, other measures should be considered to reduce the effects or even to extinguish the flame front. Unlike other protection methods that remove one or two of the explosion triangle elements, namely; the ignition source, the oxidizing agent and the fuel, explosion barriers removes all of them: reduces the quantity of coal in suspension, cools the flame front and the steam generated by vaporization removes the oxygen present in the flame.
\end{abstract}

Passive water barriers are autonomous protection systems against explosions that reduce to a satisfactory safety level the effects of methane and/or flammable dust explosions. The barriers are activated by the pressure wave provoked in the explosion destroying the barrier troughs and producing a uniform dispersion of the extinguishing agent throughout the gallery section in quantity enough to extinguish the explosion flame.

Full scale tests have been carried out in Polish Barbara experimental mine at GIG Central Mining Institute in order to determine the requirements and the optimal installation conditions of these devices for small sections galleries which are very frequent in the Spanish coal mines.

Full scale tests results have been analyzed to understand the explosion timing and development, in order to assess on the use of water barriers in the typical small crosssection Spanish galleries. Several arrangements of water barriers have been designed and tested to verify the effectiveness of the explosion suppression in each case. The results obtained demonstrate the efficiency of the water barriers in stopping the flame front even with smaller amounts of water than those established by the European standard. According to the tests realized, water barriers activation times are between $0.52 \mathrm{~s}$ and $0.78 \mathrm{~s}$ and the flame propagation speed are between $75 \mathrm{~m} / \mathrm{s}$ and $80 \mathrm{~m} / \mathrm{s}$. The maximum pressures $\left(\mathrm{P}_{\max }\right)$ obtained in the full scale tests have varied between 0.2 bar and 1.8 bar.

Passive barriers protect effectively against the spread of the flame but cannot be used as a safeguard of the gallery between the ignition source and the first row of water troughs or bags, or even after them, as the pressure could remain high after them even if the flame front has been extinguished.

Keywords: Real scale tests, Passive water barriers, Spanish coal mines, gas and coal dust explosion. 


\section{INTRODUCTION}

The presence of flammable gas and coal dust in the mine atmosphere is one of the biggest safety problems in the underground mining of coal. Although there are significant technological advances, they have not succeeded in eliminating the problem as the increased production and mechanization and electrification of the work contribute to this risk to remain. Today still very serious coal mine accidents occur, as the mine gas explosion at the Sago Mine in West Virginia, USA that left 12 dead on 2 January 2006, the Ulyanovskaya longwall coal mine explosion in the Kemerovo Oblast, Russia, killing 108 people, or the likely explosion of coal dust that caused 169 miners killed on 27 December 2005 at Donfeng mine in Heilongjiang province, China.

The firedamp adsorbed in coal mines can continuously release by decreasing pressure, increasing temperature, fragmentation of coal due to pressures from the field and any changes in physical conditions thereof [1]. Dynamic gas phenomena may also occur in some deep mines. But the greatest risk occurs as a result of desorption that takes place at the coal face, which is correlated with the mining speed.

Due to its low specific gravity, methane tends to migrate toward the roof of the galleries, and its diffusion into the mainstream is a slow process. Methane tends to accumulate in both chambers in the roof in places and high points, and it is difficult to detect in such cases. The accumulation of methane in these cavities can significantly be often higher than usual concentrations in the workings.

In addition to firedamp, it is essential to consider the risk due to coal dust [2]. At any mine dust is generated during normal operations associated with the mining and coal dust is an element that can generate flammable explosive atmospheres. Unlike firedamp whose characteristics are very stable, coal dust varies greatly in its characteristics of flammability and explosiveness, which was found to be very different in different coals. There is a correlation between the explosion of different types of coal and its composition (proximate and ultimate analysis) [3]. In general, the higher the volatile matter content of coal, the greater its flammability.

To assess the risk of explosion due to coal dust, in addition to coal properties, it is necessary to consider the mining method and seam characteristics that affect dust production, accumulation and dispersion ability [4]. It is possible to apply traditional methods of risk assessment for specific mining explosions [5]. It should be noted that the presence of mine gas produces an increase in coal explosion due to gas adsorbed [6] or the presence in air of reduced concentrations of methane [7].

\section{PASSIVE EXPLOSION WATER BARRIERS}

Explosion barriers were known for long time and included among preventive and protective measures specific to mining, as the recommendations of the Permanent Safety and Health Commission for Coal Mines and other Extraction Industries [8], the traditional methods employed in mines in Poland with high risk of explosion [9] or the earlier forms of barriers against mine explosion [10].

Explosion barriers can be grouped into passive barriers and active barriers [11]. Passive barriers can be divided in stone-dust barriers and water barriers depending on the type of inert material used (incombustible stone dust or water). Water barriers are easier to maintain, less costly and as effective as stone dust barriers.

Passive barriers base their own performance in the kinetic energy of the pressure wave moving ahead of the flame front in an explosion. When the flame of the explosion reaches the water barrier, it has already been activated by the energy associated with the pressure wave, resulting in the dispersion of 
the inert matter in the path of the flame. To be effective, water or stone dust should be completely dispersed on the arrival of the flame front.

When an explosion occurs, the pressure wave turns over, decays or even destroys the water containers, pouring its contents, so water is dispersed by the turbulence of the air and creates a barrier formed by the dispersion of water droplets along the path of the flame [12]. They are only effective under a design and layout precisely defined. When the barrier is properly positioned, the flame is extinguished. If the barrier is too far or too close to the source of the explosion, the flame cannot be effectively extinguished. Its effectiveness is based on the dispersion in the entire cross section of the gallery of water in the troughs when caught by the pressure wave that precedes the explosion, thus acting as a means for extinguishing the flames of the explosion that followed behind.

If the suppressant is dispersed prematurely, its concentration is diluted before it reaches the flame. When the suppressor agent is dispersed too late it goes after the flame and has minimal effect on the extinction of the flame. To avoid these drawbacks, the active barriers incorporate trigger mechanisms, which consist of three main components: the sensor, the distributor and the suppressor. A sensor device detects the arrival of the blast by the increase of the static pressure, temperature or radiation and triggers a mechanism to disperse the suppressor agent. The discharge is produced by a compressed gas, a spring or explosive materials [14].

\section{IMPLEMENTATION OF WATER BARRIERS IN SPANISH COAL MINES}

Experience in underground coal mining in Spain has been limited to experimental sporadic uses of passive water barriers in some individual galleries [15]. Actually in the underground mines the passive barriers are not in use as protection systems for limiting the spread of the coal dust explosions, because:

- Particular coal properties - moderate volatile content combined frequently with high ash content;

- Not very large methane emission from the seams.

Those mines are characterized by:

- Relatively small workings cross sections, rarely greater than $12 \mathrm{~m}^{2}$;

- Coal extraction mainly by the "sublevel" techniques with use of explosives.

These factors diminish the risk of coal dust explosion, but the risk reduction is not completely obtained.

The most dangerous places are coal faces where shot firing is performed.

\subsection{First steps to study the viability of water barriers}

According to preliminary study of viability it is recommended to follow several steps:

- Select one or two places where the risk of coal dust explosion is the highest according to the view of mine management as suitable places for installation of water trough barriers.

- Supply all material as water troughs, supporting elements, such as wooden shelves or metallic frames and others

- Install the barrier in the cross section according to one possible arrangement.

- Observe reaction of the mine crew and explain the idea of explosion barriers. 
- Assess the explosion risk in mine workings taking into account the coal properties, amount of settled coal dust, its humidity and incombustible content to establish the places where barriers should be installed.

- Develop coal company safety regulations for explosion prevention and protection including settled dust inertizing and then study their extension to national guidelines.

\section{EXPERIMENTAL DEMONSTRATION OF WATER BARRIER EFFECTIVENESS}

During November 2008 three water barriers full-scale tests at Barbara Experimental Mine were performed:

- Demonstration of water barrier effectiveness in a strong explosion case, with water troughs of 40 litres, $50 \mathrm{~m}^{3}$ methane, $120 \mathrm{~kg} / \mathrm{m}^{2}$ of cross section

- Demonstration of water barrier effectiveness in strong explosion case with mixed water troughs of 40 litres and 80 litres, $50 \mathrm{~m}^{3}$ of methane, $120 \mathrm{l} / \mathrm{m}^{2}$ of cross section;

\subsection{Full-scale test specifications}

Tests were carried out in the $400 \mathrm{~m}$ long underground gallery (Figure 1) having $7.5 \mathrm{~m}^{2}$ of cross section, which reflects the conditions present in most common galleries in the Spanish mining industry. On the cross section 2-2 the side shelves sections and crossbars are shown. Both elements serve to deploy the dust along the gallery. The enforced concrete gallery is built to withstand the explosions up to 45 bar. At the wall the sensors of flame and pressure are mounted. Flame sensors are positioned every $20 \mathrm{~m}$, pressure sensors are placed every $20 \mathrm{~m}$ at the first $100 \mathrm{~m}$, and every $40 \mathrm{~m}$ after that.

As an ignition source a methane chamber with $50 \mathrm{~m}^{3}$ was applied, with $4.5 \mathrm{~kg}$ of coal dust deployed in front of the paper baffle closing the methane chamber.

The objective of the test is to show that the explosion propagation is stopped when using the installation requirements defined in the standard EN 14591-2 [13].

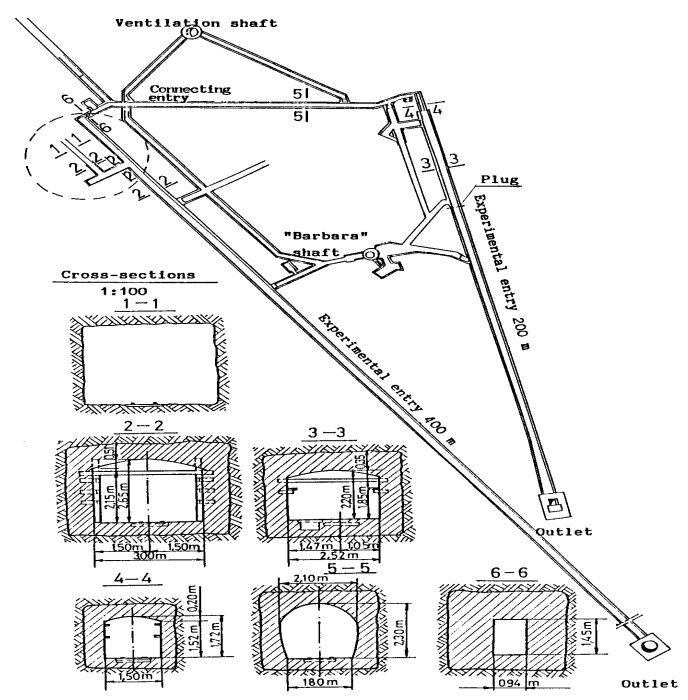

Figure 1. Underground Experimental galleries in the Experimental Mine "Barbara"

The chamber is filled with methane/air mixture in concentration about 9.5\% (stoichiometric mixture) and ignited with a detonator. Primary explosion of methane gives sufficient blast and temperature to 
lift and ignite coal dust in front of the chamber and consequently start the coal dust explosion at the gallery.

The tested water trough barrier was arranged at a distance of $100 \mathrm{~m}$ from the closed end of the gallery and extended up to $121 \mathrm{~m}$. This barrier contains $120 \mathrm{l}$ of water per square meter of roadway cross section. Such amount is 60\% of the amount of water required by standard EN 14591-2:2007 and is used in most national regulations to demonstrate the barriers effectiveness. In practice double amount is used to enhance the barrier reliability. Tested barrier was placed inside the dusty zone to be sure that explosion propagation is interrupted by the action of barrier and not by lack of dust in the gallery.

\subsection{Test 1: demonstration of water barrier effectiveness in strong explosion case, with water troughs}

Test conditions for strong explosion, with water troughs of 401 were:

\section{- Ignition source}

In 6-6 gallery cross-section the gas chamber was filled with a volume of $50 \mathrm{~m}^{3}$ having a $9.5 \%$ methane/air stoichiometric mixture closed with a paper baffle. This mixture was ignited with $500 \mathrm{~g}$ of black powder in the mortar and was ignited by a detonator. In front of the chamber, along a $2.5 \mathrm{~m}$ length gallery, $4.5 \mathrm{~kg}$ of coal dust mass were spread with a nominal concentration of $0.250 \mathrm{~kg} / \mathrm{m}^{3}$. Coal dust was deployed on the horizontal shelves. When the methane explosion was started the blast wave lifted the coal dust and dispersed it in the air, and the proper dust explosion was initiated in the gallery. This dust contained 38\% material passing $0.075 \mathrm{~mm}$ sieve (200mesh). The volatile content of coal dust sample was $38.5 \%$.

\section{- Dust zone}

$156.6 \mathrm{~m}$ of 6-6 gallery contained coal dust on side shelves and roof bars. The total amount of deployed coal dust was $340 \mathrm{~kg}$ and the nominal dust concentration in the dust zone was $0.300 \mathrm{~kg} / \mathrm{m}^{3}$.

\section{- Water trough barrier}

Water troughs were supplied by the Polish manufacturer Radom and they were certified according to EN-14591-2:2007. The water barrier was composed by a total of 7 rows with 3 troughs of 40 litres volume in each row. The horizontal distance between two rows was $3 \mathrm{~m}$ and the total length was 21 $\mathrm{m}$. The water troughs were set from $100 \mathrm{~m}$ up to $121 \mathrm{~m}$ of the gallery. The total water amount was 840 litres, 120 litres in each row and water concentration in barrier location was $5.3 \mathrm{~kg} / \mathrm{m}^{3}$ or $112 \mathrm{1} / \mathrm{m}^{2}$.

The test record (shown in Figure 2) indicated that the dust explosion was stopped inside the dust zone. 


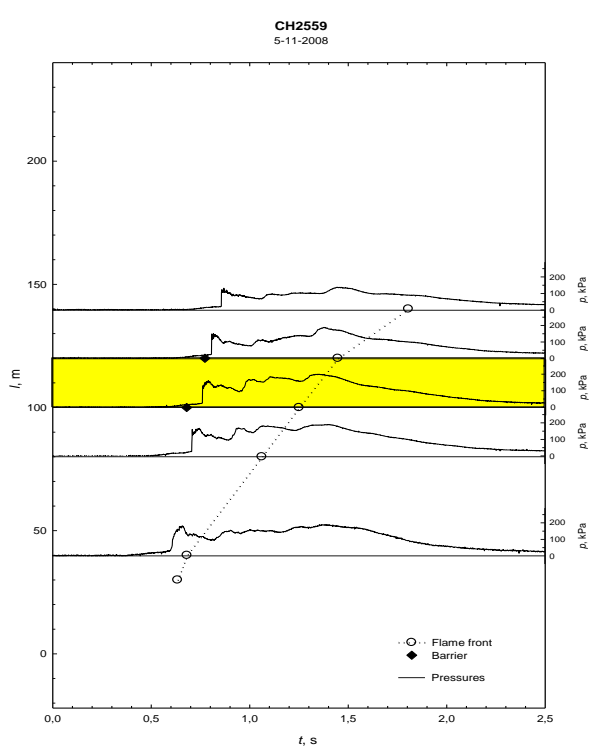

Figure 2. The water barriers efficiency in case of strong explosion with 401 water troughs

\subsection{Test 2: demonstration of water barrier effectiveness in strong explosion case with mixed water troughs of 40 litres and 80 litres}

Test conditions regarding to ignition source and dust zone for strong explosion with mixed water troughs of 40 litres and 80 litres are identical to those of Test 1:

\section{- Water trough barrier}

Water troughs were supplied by the Polish manufacturer Rybnik and they were certified according to EN-14591-2:2007. The water barrier was composed by a total of 7 rows (6 rows with 3 troughs of 401 volume in each row and one row with two troughs of 801 volume). The horizontal distance between two rows was $3 \mathrm{~m}$ and the total length was $21 \mathrm{~m}$. The water troughs were set from $100 \mathrm{~m}$ up to $121 \mathrm{~m}$ of the gallery.

The total water amount was 880 litres and water concentration in barrier location was $5.6 \mathrm{~kg} / \mathrm{m}^{3}$ or $117,31 / \mathrm{m}^{2}$.

The test record (shown in Figure 3) indicated that the dust explosion was stopped inside the barrier zone. 


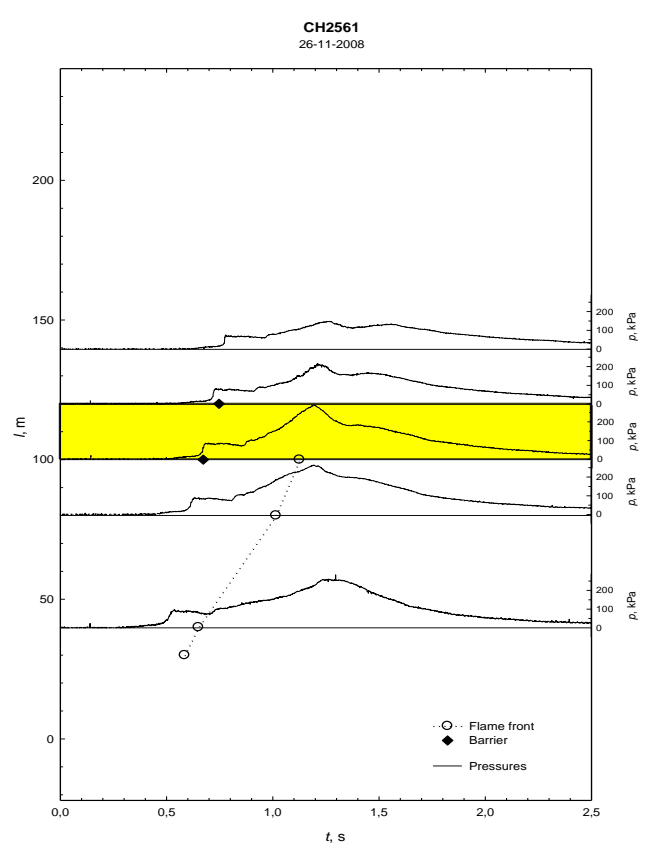

Figure 3. The water barriers efficiency in case of strong explosion with mixed $401+801$ water troughs

\section{DISCUSSION}

Tests 1 and 2 probed an adequate efficiency of water barriers to stop strong explosions, even using $60 \%$ of the amount of water required by standard. The explosion records did not leave any doubt about the actuation of the barrier and the inspection after test allowed verifying the correct operation of the water troughs.

Water barrier arrangement used in test 3, consisting of a mixed distribution of 40 litre and 80 litre trough can be considered as more adequate for the Spanish mines, because more flame traces have been registered by the sensors for the 401 distribution water troughs than for the mixed distribution of $401+801$ troughs showing that he explossion was contained sooner with the mixed trough distribution

\section{CONCLUSSIONS}

Spanish coals are not extensively explosive, being characterized by relatively low volatile content (frequently less than 15\%) and high ash content (average about 30\%). These two factors diminish the explosion risk. Water barriers will be implemented after detailed risk assessment in the workings where there is an elevated explosion risk. This evaluation should include a thorough analysis of the flammability characteristics of coal dust and the feasibility of inerting coal dust should always be considered.

A general conclusion obtained from the underground tests is that passive water barrriers are effective in the arrest of coal dust explosions in galleries of reduced section. The effectiveness greatly depends on the configuration of the barriers. The test at the mixed configuration (40 and 80 litre troughs) has yielded the best results.

For reduced section galleries with unobstructed sections the installation of passive water barriers according to the EN 14591-2 is possible. However, the execution of mining works in reduced section galleries together with the installation of different equipment significantly reduces the effective section and it is very difficult or even unfeasible to install passive water barriers as required by EN 14591-2. 
For many existing forms of mining in Spain (longwall, and soutirage sublevels by room and pillar) the EN 14591-2 standard does not specify clearly which are the locations for installing passive water barriers. The standard can be difficult to be properly applied as it is necessary to draft a guide and perhaps some additional rules or regulations.

\section{ACKNOWLEDGEMENTS}

The authors thank the Spanish Directorate General for Energy Policy and Mines Ministry of Industry, Commerce and Tourism (Dirección General de Política Energética y Minas del Ministerio de Industria, Comercio y Turismo) for funding this work (project code: 080601001-13)

\section{REFERENCES}

[1] Cybulski, W. "Coal dust explosions and their suppression”. National Science Foundation. (1975).

[2] Lebecki, K. et al. "Specific conditions for the initiation of coal dust explosions". HSE (Przeglad Górniczy), 7-8 (1981).

[3] García Torrent, J., Sánchez Armada I., Alcántara Pedreira, R. "A correlation between composition and explosibility index for coal dust", FUEL, 67, (1988).

[4] García Torrent, J.; Querol Aragón, E.; Fernández Ramón, C.; Carrasco Galán, J. "Definition of explosion risk assessment procedures in explosive atmospheres of coal dust in underground mine workings". III Safety Symposium in Mining and Allied Industries. Madrid. Ministry of Economy. Deputy General Directorate of Mines. LOM-UPM (2001).

[5] García Torrent, J.; Querol Aragón, E. "Application of analytical methods for evaluating the risk of explosion in underground mining". Congress on safety, quality and environment in Mining Engineering. Barcelona (2003).

[6] García Torrent, J., Arévalo, J.J. "Increase in coal explosibility due to methane adsorption". 25th Int. Conf. Safety Mines Research Institute. Pretoria Session 5a (1993).

[7] García Torrent, J.; Cantalapiedra Fuchs, J. "Flammability and explosion propagation of methane-coal dust hybrid mixtures". 23rd. International Conference of Safety in Mines Research Institutes. Washington. US Department of the Interior, Bureau of Mines (1989).

[8] Permanent Safety and Health Commission for Coal Mines and other Extraction Industries "Measures to reduce risks of fire and explosion in the mine workings with secondary ventilation and improvement in the protection of personnel in case of fire and explosion at coal mines". Doc. № 5147/89 FR. Luxemburg (1990).

[9] K.Lebecki; "Developments of water barrier to stop coal dust explosion; Conference on Mining Environment and Ventilation”, New Delhi and Calcutta, Oxford \& IBH Publishing Company (2000).

[10] Lunn G.A. (1985). "Dust explosions: barrier methods for industry". Health and Safety Executive.

[11] Zou, D.H.; Panawalage, S. "Passive and Triggered Explosion Barriers in Underground Coal Mines - A literature review of recent research". CANMET Natural Resources Canada. (2001).

[12] K.Lebecki , K.Cybulski, Z.Dydyuch. "Test results and practical use of water bags barriers"; Proceedings of the 29th International Conference of safety in Mines Research Institutes, Katowice GIG, Poland (2001)

[13] EN 14591-2:2007 "Explosion prevention and protection in underground mines - Protective systems - Part 2: Passive water trough barriers".

[14] Lebecki, K., Sliz, J., Cybulski, K. \& Dyduch, Z. "Efficiency of triggered barriers in dust explosion suppression in galleries". Journal of Loss Prevention in the Process Industries, 14, (2001)

[15] García Torrent, J. "A review of protection measures against explosions in underground mining” (Revisión de medidas de protección contra explosiones en la minería subterránea de carbón). Canteras y Explotaciones, 304, (1992). 